\title{
ARTIGOS
}

\section{Patogenicidade cruzada de Ceratobasidium spp. do caquizeiro (Diospyros kaki) e do chá(Camellia sinensis) e reação de cultivares de caqui ao patógeno.}

\author{
Elaine Costa Souza ${ }^{1}$, Marco Antonio Basseto ${ }^{1}$, Aparecida Conceição Boliani² ${ }^{2}$ Hélio Minoru Takada ${ }^{3}$, Paulo Cezar Ceresini ${ }^{1,4}$
}

${ }^{1}$ UNESP - Campus de Ilha Solteira, Departamento de Fitossanidade, Engenharia Rural e Solos e ${ }^{2}$ Departamento de Fitotecnia, Economia e Sociologia Rural; APTA Pólo Regional do Vale do Paraíba, Pindamonhangaba, SP; ${ }^{4}$ ETH Zurich - Swiss Federal Institute of Technology, IBZ Institute of Integrative Biology - Plant Pathology, Zurique, Suíça; Financiamento FAPESP (04/01980-0) e Convênio ETH Zurich - UNESP

Autor para correspondência: Paulo Cezar Ceresini paulo.ceresini@agrl.ethz.ch

Data de chegada: 01/02/2007. Aceito para publicação em: 01/12/2008

\section{RESUMO}

Souza, E.C.; Basseto, M.A.; Boliani, A.C.; Takada, H.M.; Ceresini, P.C.. Patogenicidade cruzada de Ceratobasidium spp. do caquizeiro (Diospyros kaki) e do chá (Camellia sinensis) e reação de cultivares de caqui ao patógeno. Summa Phytopathologica, v.35, n.1, p.09-14, 2009

O fungo Ceratobasidium spp. é o agente causal da doença mal-dofio ou queima-do-fio em várias plantas frutíferas, em cafeeiro e em chá. Esta doença ocorre com maior freqüência em zonas de alta precipitação e temperaturas elevadas, típicas de regiões de florestas tropicais como a Amazônica e a Mata Atlântica. Em São Paulo, o primeiro relato do mal-do-fio em caquizeiro ocorreu na região de Mogi das Cruzes. O objetivo deste estudo foi testar a patogenicidade cruzada de isolados de Ceratobasidium spp. de caquizeiro e chá para ambas as culturas e também para o cafeeiro e citros. Avaliou-se, também, a reação de oito cultivares de caquizeiro, sob condições controladas, a isolados de Ceratobasidium spp. obtidos da mesma cultura. Constatouse que os isolados de caquizeiro e de chá, embora filogeneticamente distintos, foram patogênicos para ambas as culturas, além de afetarem cafeeiro e citros. Não foram verificados indícios de reação de resistência aos isolados de Ceratobasidium spp. para as oito cultivares de caquizeiro testadas.

Palavras-chave adicionais: fungo basidiomiceto, resistência, cafeeiro, citros, Rhizoctonia binucleada

\section{ABSTRACT}

Souza, E.C.; Basseto, M.A.; Boliani, A.C.; Takada, H.M.; Ceresini, P.C.. Cross pathogenicity of Ceratobasidium spp. from kaki (Diospyros kaki) and tea (Camellia sinensis) and reaction of kaki varieties to the pathogen. Summa Phytopathologica, v.35, n.1, p.09-14, 2009

The fungus Ceratobasidium spp. causes the white-thread blight disease, which affects several fruit trees, coffee and tea crops. This disease frequently occurs in zones of high precipitation and temperatures, typical of the tropical forest regions such as the Amazon and the Atlantic Forests. In São Paulo State, Brazil, this disease was reported by the first time affecting kaki plants in Mogi das Cruzes county. The objective of this study was to test the cross-pathogenicity of Ceratobasidium spp. isolates from kaki and tea to both host plants and also to coffee and citrus. This study also aimed to determine the reaction of local kaki varieties to Ceratobasidium spp. isolates from kaki under controlled conditions. Although phylogenetically distinct, kaki- and tea-infecting isolates were cross-pathogenic to both hosts, besides infecting coffee and citrus. There was no indication of resistance reaction among the eight kaki varieties tested.

Keywords: Basidiomycete fungus, resistance, coffee, citrus, binucleate Rhizoctonia

As doenças constituem grande problema para a cultura do caquizeiro (Diospyrus kaki L.) podendo reduzir drasticamente a sua produção (5). Entre as doenças relatadas, a queima-do-fio, também conhecida como mal-do-fio, causada pelo fungo Ceratobasidium spp., tem adquirido importância. O patógeno já foi relatado afetando uma série de culturas no mundo, com distribuição na maioria dos continentes. Na América há relatos da doença em vários paises como Argentina, Brasil, Colômbia, Venezuela, Guianas, entre outros da América Central, México e EUA (4). Esta doença é bem conhecida na região Amazônica, afetando um grande número de plantas frutíferas (9).

O primeiro relato de um patógeno semelhante no Brasil data de 1980, quando Rosseti e colaboradores descreveram a ocorrência de sintomas parecidos à queima-do-fio em plantas de pomelo oriundos do estado do Amazonas, sendo inicialmente classificado como Pellicularia koleroga (16). Até 1987, 27 espécies de plantas haviam sido relatadas como hospedeiras do patógeno na região Amazônica (11). Em 1999, outras 18 espécies de plantas fruteiras nativas da Amazônia foram descritas como hospedeiras de P. koleroga (Koleroga noxia) (9). A doença já foi descrita afetando culturas como gravioleira (Anona muricata L.), pimenteira-preta (Pipper nigrum L.), cacaueiro (Theobroma cacao L.), Citrus sp., cafeeiro (Coffea arabica L.), mangueira (Mangifera indica L.), seringueira [Hevea brasiliensis (Willd. ex Adr. de Juss.) Muell. \& Arg.] e diversas outras árvores frutíferas do Amazonas (7; 10; 12; 16). Em São Paulo (SP), a queimado-fio foi relatada afetando chá [Camellia sinensis (L.) O. Kuntze] no Vale do Ribeira (8). Recentemente, a doença foi relatada afetando 
caquizeiro na região de Mogi das Cruzes, SP (13).

A queima-do-fio é a doença mais freqüente em zonas de alta precipitação e temperaturas elevadas como nas florestas tropicais da Amazônia e da Mata Atlântica. A doença aparece e se desenvolve durante a estação chuvosa, com sintomas visíveis nas folhas, ramos e frutos novos. A infecção ocorre na parte inferior dos ramos e avança da base até a extremidade do ramo em forma de cordões finos esbranquiçados, que se ramificam abundantemente pelas folhas, chegando a cobri-las totalmente, formando uma película branca e semitransparente que se escurece com o tempo. As folhas tornamse escuras, secam e ficam penduradas no ramo por cordões miceliais (5).

O gênero Ceratobasidium é um Basidiomiceto que tem como fase anamórfica espécies binucleadas de Rhizoctonia (18). Muitas das espécies de Rhizoctonia binucleadas, entretanto, estão frequentemente associadas com controle biológico $(2 ; 3 ; 18)$.

A verdadeira identidade do agente causal da queima-do-fio era questionada até recentemente. O fitopatógeno foi caracterizado inicialmente como P. koleroga, mas poucas descrições das características morfológicas do fungo foram publicadas (11). Atualmente, as espécies causadoras da queima-do-fio em diversas plantas arbóreas estão agrupadas no gênero Ceratobasidium, mais precisamente $C$. anceps, $C$. cornigerum ou C. noxium (15). Ceresini et al. (6) detectaram, através de reconstrução filogenética clássica e por análise coalescente, duas populações distintas de Ceratobasidium associadas ou à queima-do-fio do caquizeiro ou à do chá no Estado de São Paulo. Embora compartilhando um mesmo ancestral, constatou-se distinção filogenética entre populações de isolados de Ceratobasidium spp. que atacam o caquizeiro e o chá, as quais foram denominadas grupo Diospyrus e grupo Camellia, respectivamente. Estas duas populações de Ceratobasidium spp. foram também descritas como filogeneticamente distintas tanto de C. noxium (originalmente descrito como o agente causal etiológico da doença em cafeeiro) quanto de C. cornigerum (a espécie filogeneticamente mais próxima). Estas populações provavelmente constituem duas novas espécies de Ceratobasidium que devem ser nomeadas e formalmente descritas. Como estes dois grupos ainda não estão formalmente definidos como espécies novas, optou-se por utilizar a designação ampla de Ceratobasidium spp., e de grupo Diospyrus e grupo Camellia quando nos referirmos aos grupos filogeneticamente distintos do patógeno.

Várias pesquisas foram desenvolvidas para compreender os aspectos relativos à epidemiologia e controle de Ceratobasidium spp. Entretanto, não há informação sobre a patogenicidade cruzada de isolados de Ceratobasidium spp. que infectam caquizeiro para outras plantas hospedeiras, assim como sobre a patogenicidade cruzada, ao caquizeiro, de isolados que infectam chá.

O objetivo principal deste estudo foi testar a patogenicidade cruzada de isolados de Ceratobasidium spp. de caquizeiro e de chá para ambas as plantas hospedeiras e para o cafeeiro e o citros, bem como avaliar a reação de oito cultivares de caquizeiro ao fitopatógeno.

Baseando-se em informação a priori de que isolados de Ceratobasidium spp. do caquizeiro e do chá constituem grupos filogeneticamente distintos (6), nossa hipótese (Ho) a respeito da patogenicidade a hospedeiros distintos foi de que isolados de Ceratobasidium spp. do grupo Camellia e do grupo Diospyrus não apresentam patogenicidade cruzada. Nossa segunda hipótese foi de que não há variação genética para resistência ao mal-do-fio em cultivares de caqui.

\section{MATERIAL E MÉTODOS}

\section{Patogenicidade cruzada}

O estudo da patogenicidade cruzada dos isolados de Ceratobasidium spp. de caqui e de chá foi conduzido utilizando-se sete cultivares de caquizeiro (Fuyu, Giombo, Giro, Pomelo, Rama Forte, Regina e Rubi); uma de café [Mundo Novo (IAC 502-1)]; uma de chá (IAC 259) e uma de citros (laranja Pêra IAC-2000). Foram conduzidos dois experimentos: um sob condição de casa de vegetação e outro em estufa incubadora (BOD). No segundo experimento, foram utilizados ramos destacados das mesmas plantas mantidas em casa de vegetação, após poda para estímulo de brotação.

A inoculação do fitopatógeno nas plantas hospedeiras seguiu adaptação do método de inoculação pela deposição, nos ramos das plantas, de palitos de madeira (tipo “palito-de-dentes”) colonizados por micélio do fungo (17). No experimento conduzido em casa de vegetação foram utilizados três tratamentos: a) inoculação com isolados de Ceratobasidium spp. de caquizeiro [mistura dos isolados DK_CAF (de folhas infectadas) e DK_CAC (de caule infectado) obtidos em Guararema, SP]; b) inoculação com isolado de chá escolhido aleatoriamente da população de Ceratobasidium spp. amostrada de chá obtida no Vale do Ribeira, SP; c) testemunha não inoculada. Os isolados de caquizeiro representam o haplótipo HDk1 da região ITS5.8S do rDNA mais freqüentemente amostrado na população de Ceratobasidium spp. do caquizeiro em SP (6).

A inoculação foi efetuada transferindo-se palitos colonizados pelo fungo para a superfície dos ramos previamente feridos no ponto de inoculação. Estes palitos haviam sido mantidos por sete dias sobre culturas de Ceratobasidium spp. crescidas em meio de BDA (batatadextrose - agar) a $25^{\circ} \mathrm{C}$. Os palitos colonizados ou não foram fixados ao ramo dos hospedeiros com auxílio de filme plástico. Após a inoculação, os ramos foram mantidos sobre condição de câmara úmida em sacos de plástico umedecidos, até o momento da avaliação. Às testemunhas foram transferidos palitos não infestados pelo fungo, mantidos sob a superfície de meio de BDA pelo mesmo tempo de incubação do fungo.

O delineamento experimental foi o de blocos inteiramente casualizados num esquema fatorial do tipo $3 \times 4$ com fatores representados por isolados de Ceratobasidium spp. do caquizeiro ou do chá mais o tratamento não inoculado versus espécies de plantas (caquizeiro, cafeeiro, chá e citros). As parcelas experimentais representadas pelo tratamento caquizeiro foram subdivididas em sete cultivares. No experimento em casa de vegetação foram utilizados cinco repetições por tratamento (inclusive para as testemunhas não inoculadas de cada cultivar de caquizeiro e de cada espécie de planta testada). Em cada vaso de 10 a $20 \mathrm{~L}$ de volume de solo (dependendo da espécie de planta) foi mantida uma planta. A inoculação do fungo foi efetuada em brotações jovens das plantas (de 17 a 20 dias de idade). A condição de alta umidade relativa do ar foi mantida de forma contínua durante todo o período de permanência na casa de vegetação, através de nebulização automática, e da manutenção, por sete dias, de um saco plástico envolvendo o ramo inoculado.

O segundo experimento foi conduzido em estufa incubadora, com delineamento semelhante ao primeiro. A inoculação foi semelhante à utilizada no experimento em casa-de-vegetação, porém para a inoculação dos ramos das plantas, ao invés de se usar um ou dois isolados de cada um dos hospedeiros, optou-se por utilizar dois grupos de isolados, um de isolados de Ceratobasidium spp. do caquizeiro e outro de chá. Assim, evitou-se problemas oriundos de possível variabilidade 
patogênica entre os isolados de cada grupo. Cada grupo de isolados foi transferido de maneira independente para placas contendo meio de BDA com palitos de madeira para colonização, representando placas de isolados de caquizeiro e de chá. O inóculo de Ceratobasidium spp. do caquizeiro compôs-se do seguinte grupo de isolados: Dk_2c, Dk_5e, Dk_6a, Dk_6d, Dk_9e, Dk_10a, Dk_10c, Dk_11b, Dk_12a, Dk_12d, Dk_CAC e Dk_CAF. Já o inóculo de Ceratobasidium spp. do chá compôs-se do seguinte grupo de isolados: Cs_13, Cs_16, Cs_24, Cs_62, Cs_63, Cs_72, Cs_76, Cs_81, Cs_91, Cs_94, Cs_101, Cs_102, Cs_103, e Cs_108. Estes isolados representaram a maioria dos haplótipos da região ITS-5.8S do rDNA amostrados das populações de Ceratobasidium spp. de caquizeiro e de chá (6).

Foram utilizadas duas estufas incubadoras, onde cada repartição da estufa representou um bloco contendo todas as parcelas experimentais, totalizando cinco repetições de cada planta inoculada. Para inoculação foram utilizados ramos de brotações novas coletados das mudas em estádio ativo de desenvolvimento, após cerca de 20 dias do início das brotações. Cada parcela experimental, nesse caso, foi representada por um ramo destacado. As extremidades dos ramos destacados foram envolvidas em algodão esterilizado umedecido, e acondicionados em sacos plásticos. As condições de inoculação foram semelhantes às descritas para o ensaio anterior. Os ramos inoculados com palitos colonizados ou não pelo fungo foram incubados por sete dias em estufa incubadora biológica a $25^{\circ} \mathrm{C}$, com fotoperíodo de $12 \mathrm{~h}$.

Nos dois experimentos, os ramos de todas as parcelas experimentais foram fotografados com o intuito de registrar a colonização ou não dos tecidos dos hospedeiros pelos respectivos inóculos do patógeno, visando posteriormente avaliação da patogenicidade cruzada. O parâmetro avaliado foi a colonização ou não de tecidos dos hospedeiros pelos inóculos do patógeno.

Reação de cultivares de caquizeiro a Ceratobasidium ssp.

Foi avaliada a reação de oito cultivares de caquizeiro disponíveis na Fazenda de Ensino e Pesquisa da UNESP - Campus de Ilha Solteira: Taubaté, Fuyuhana, Giombo, Pomelo, Fuyu, Rubi, Rama forte e Giro. A inoculação do fungo seguiu a metodologia citada anteriormente, usando-se palitos de madeira colonizados pelo fungo, utilizando inóculo composto por mistura dos isolados de Ceratobasidium spp. Dk_CAF e Dk_CAC.

A exemplo do que foi utilizado no segundo experimento do teste de patogenicidade, nesta etapa foram utilizados ramos destacados das oito cultivares de caquizeiro coletados em campo. Os ramos foram obtidos de plantas em estágio ativo de desenvolvimento, seguindo a metodologia utilizada no segundo experimento da etapa anterior. Cada parcela experimental, nesse caso, foi representada por um ramo destacado (contendo brotações jovens, de 17-20 dias de idade), com cinco repetições para cada cultivar testada, em delineamento inteiramente ao acaso.

Para avaliação da severidade da doença, os ramos inoculados de todas as parcelas experimentais foram fotografados. Determinouse a porcentagem da área foliar e o número de folhas infectadas de uma sub-amostra de ramos de caquizeiro infectados pelo patógeno. Construiu-se, então, uma escala de notas para avaliação da severidade da doença, baseando-se em recomendações de Azevedo (1) para construção de escalas de severidade (Figura 1). Este experimento foi repetido duas vezes e seus dados foram analisados conjuntamente por meio de análise não-paramétricas sendo suas medianas comparadas entre si por meio do teste de Dunn, observando as semi-amplitudes interquartílicas. A mediana
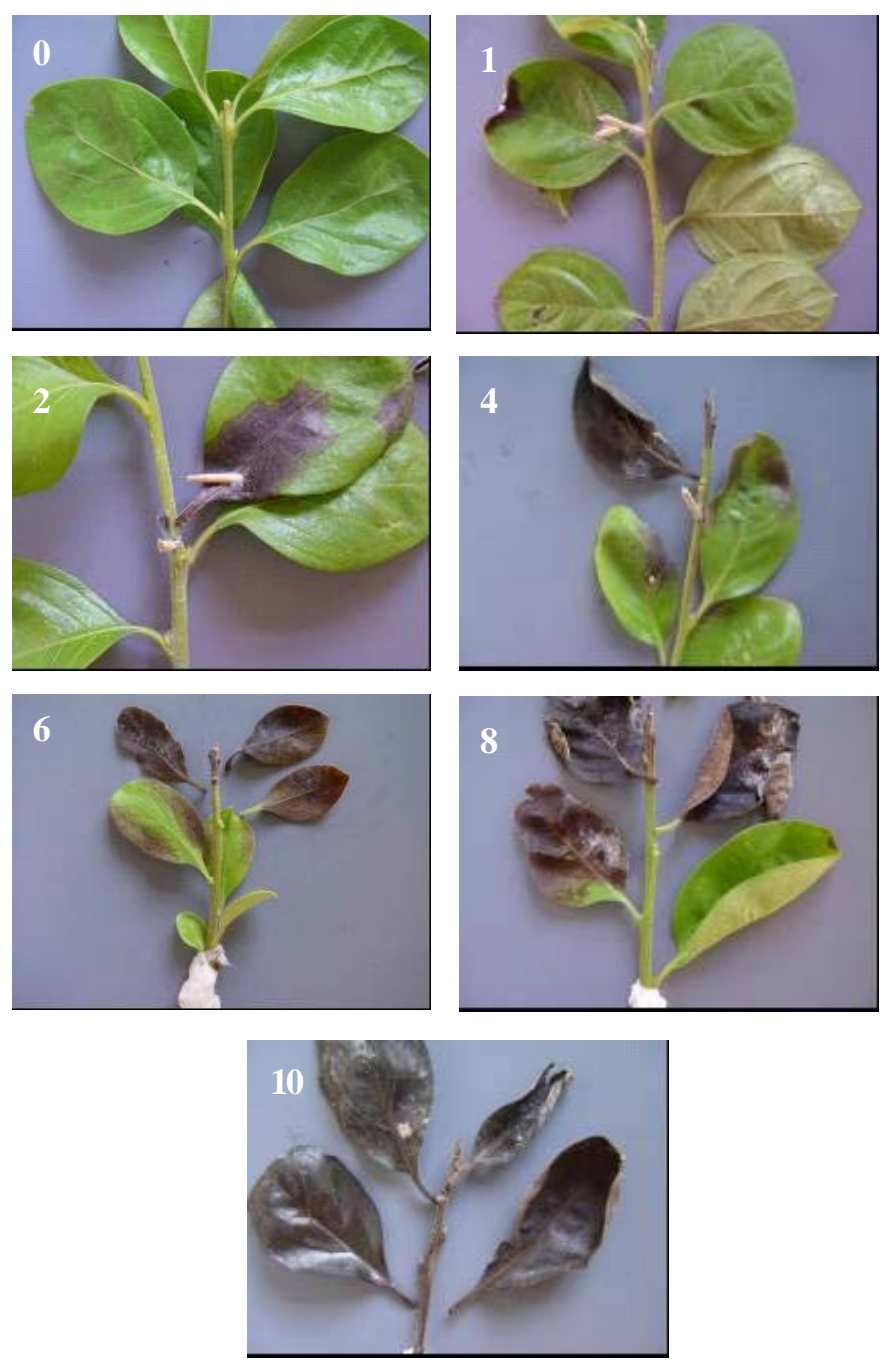

Figura 1. Escala de notas para avaliação da severidade da queima-do-fio (Ceratobasidium spp. grupo Diospyrus) do caquizeiro: 0 (0\% de área foliar infectada), 1 (1 a 10\% de área foliar infectada restrita as folhas do ponteiro), 2 (11 a 20\%), 4 (21 a 40\% de área foliar do ponteiro até a segunda folha abaixo), 6 (41 a $60 \%$ de área foliar do ponteiro até a terceira folha abaixo), 8 (61 a 80\%) e 10 (81 a 100\% de área foliar infectada e de todas as folhas do ramo). Escala de notas estabelecida de acordo com Azevedo (1).

compreende o valor central de uma série de observações, tal que a freqüência dos valores inferiores é igual a dos valores superiores. Já a semi-amplitude interquartílica diz respeito à forma com que os dados se distribuem com relação às medianas (14). O programa estatístico utilizado foi GraphPad InStat, versão 3.06 (GraphPad Software).

\section{RESULTADOS E DISCUSSÃO}

Sete dias após a inoculação, pode-se observar intensa colonização superficial dos tecidos das plantas pelo crescimento micelial do fungo, nos tratamentos com isolados de Ceratobasidium spp. de caquizeiro e de chá, em todas as cultivares de caquizeiro testadas e plantas de cafeeiro (Mundo Novo), chá (IAC 259) e citros (Pêra - IAC 2000) (Tabela 1, Figuras 2 e 3). Apesar da colonização micelial intensa das plantas inoculadas com Ceratobasidium spp. do caquizeiro e do chá (Figuras 2 e 3), não houve manifestação de sintomas mais severos, como a queima de folhas e a produção de fios ou cordões miceliais. 
Tabela 1. Patogenicidade do fungo do mal-do-fio (Ceratobasidium spp. grupos Diospyrus e Camellia) a sete variedades de caquizeiro e patogenicidade cruzada a plantas de cafeeiro, caquizeiro, chá e citros, em condições de casa de vegetação.

\begin{tabular}{|c|c|c|c|c|c|}
\hline \multirow{2}{*}{$\begin{array}{l}\text { Condições } \\
\text { experimentais }\end{array}$} & \multirow{2}{*}{ Culturas } & \multirow{2}{*}{ Cultivares } & \multicolumn{2}{|c|}{ Grupos de isolados* } & \multirow{2}{*}{$\begin{array}{c}\text { Testemunha } \\
\text { não-inoculada* }\end{array}$} \\
\hline & & & Caqui & Chá & \\
\hline \multirow{10}{*}{ 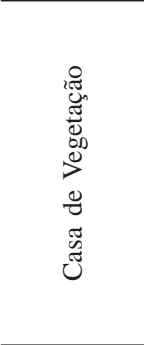 } & \multirow{7}{*}{ Caquizeiro } & Fuyu & + & + & - \\
\hline & & Giombo & + & + & - \\
\hline & & Giro & + & + & - \\
\hline & & Pomelo & + & + & - \\
\hline & & Rama forte & + & + & - \\
\hline & & Regina & + & + & - \\
\hline & & Rubi & + & + & - \\
\hline & \multirow{3}{*}{$\begin{array}{c}\text { Cafeeiro } \\
\text { Chá } \\
\text { Citros }\end{array}$} & Mundo Novo & + & + & - \\
\hline & & IAC 259 & + & + & - \\
\hline & & Pêra - IAC 2000 & + & + & - \\
\hline \multirow{10}{*}{ 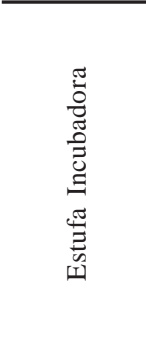 } & \multirow{7}{*}{ Caquizeiro } & Fuyu & + & + & - \\
\hline & & Giombo & + & + & - \\
\hline & & Giro & + & + & - \\
\hline & & Pomelo & + & + & - \\
\hline & & Rama forte & + & + & - \\
\hline & & Regina & + & + & - \\
\hline & & Rubi & + & + & - \\
\hline & Cafeeiro & Mundo Novo & + & + & - \\
\hline & Chá & IAC 259 & + & + & - \\
\hline & Citros & Pêra - IAC 2000 & + & + & - \\
\hline
\end{tabular}

Os símbolos + ou - indicam colonização de tecidos dos hospedeiros pelos respectivos inóculos do patógeno.

*Observações efetuadas em cinco repetições.

A
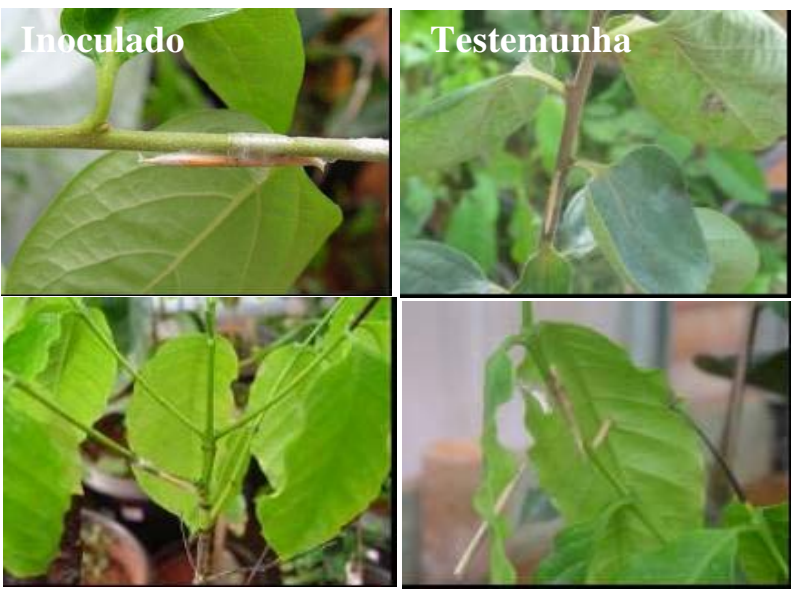

B
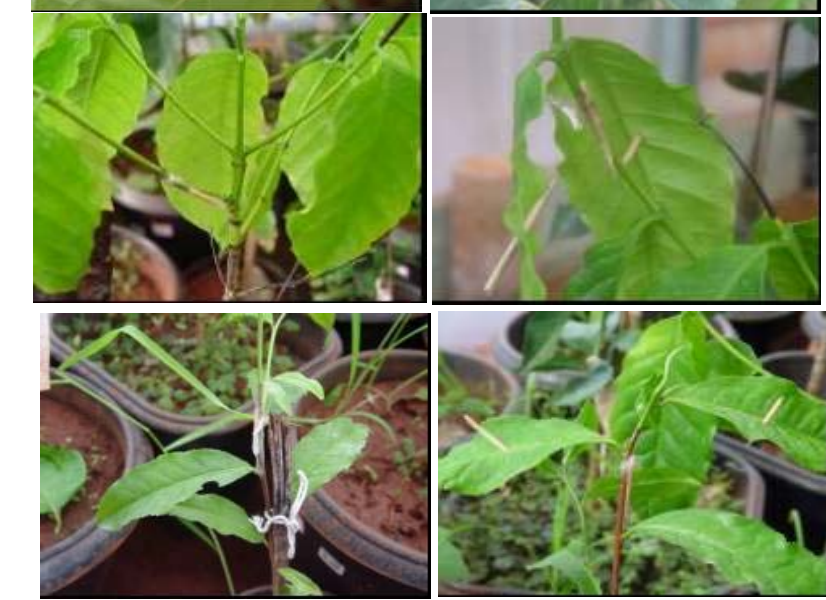

C

D
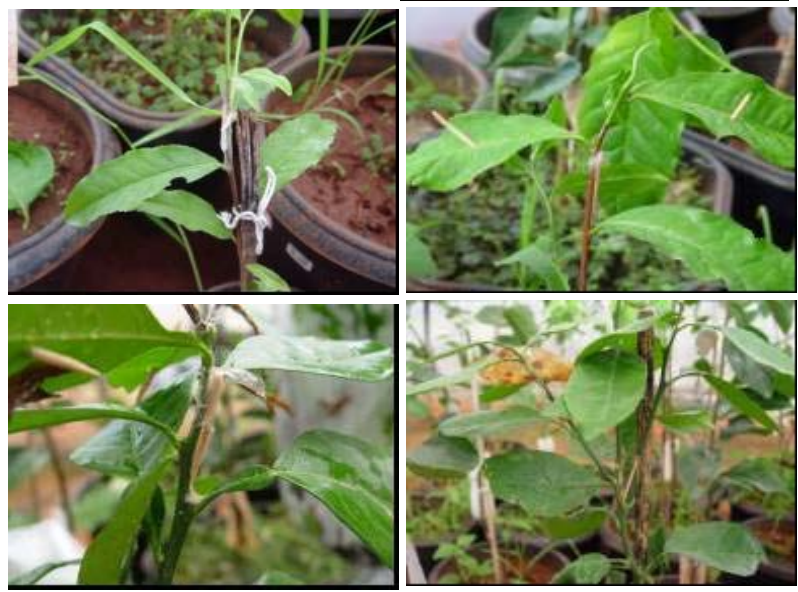

Figura 2. Colonização de órgãos aéreos de plantas de caqui (A), café (B), chá (C) e citros (D) por Ceratobasidium spp. grupo Diospyrus sob condições de casa de vegetação, 21 dias após a inoculação. Ilha Solteira, SP. As testemunhas não inoculadas de cada uma das espécies testadas são apresentadas à direita.
Evidenciou-se, assim, que mesmo sendo filogeneticamente distintos (6), os dois grupos de isolados de Ceratobasidium spp. do caquizeiro e do chá têm patogenicidade cruzada aos hospedeiros testados. Isto poderia ser uma indicação de que já ocorreu especiação entre os grupos filogeneticamente distintos de Ceratobasidium spp. do mal-do-fio (grupo Diospyrus e grupo Camellia), mas o fungo ainda mantém uma gama de hospedeiros ampla, especialmente como hospedeiros de reserva.

O fato do não aparecimento dos sintomas clássicos do mal-do-fio pode ser explicado, por exemplo, em virtude da idade das brotações dos ramos utilizados na inoculação, onde os tecidos de alguns ramos já se apresentavam mais velhos e lignificados pela falta de uniformidade entre as cultivares de caquizeiro na época de emissão de brotações. Houve dificuldade também, em se obter, na mesma época, brotações jovens das demais espécies de plantas testadas.

Outro fator que pode ter limitado o desenvolvimento mais severo da doença está associado com as condições de condução do experimento. No campo, a doença é mais severa durante períodos chuvosos, com temperaturas elevadas, onde associados ao adensamento da área foliar das plantas pelo intenso crescimento vegetativo, forma um microclima favorável para que o fungo se desenvolva (5). Entretanto, o sistema de nebulização da casa de vegetação não funcionou de forma regular. Assim, para manutenção das condições de umidade foi necessário manter (por uma semana)

A
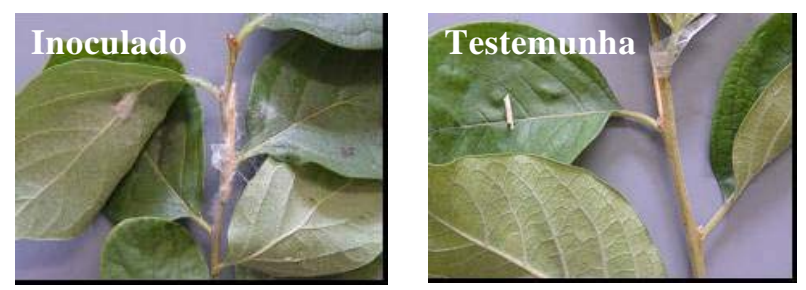

B
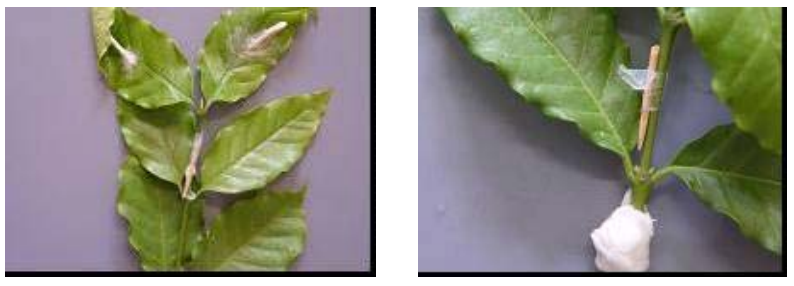

C
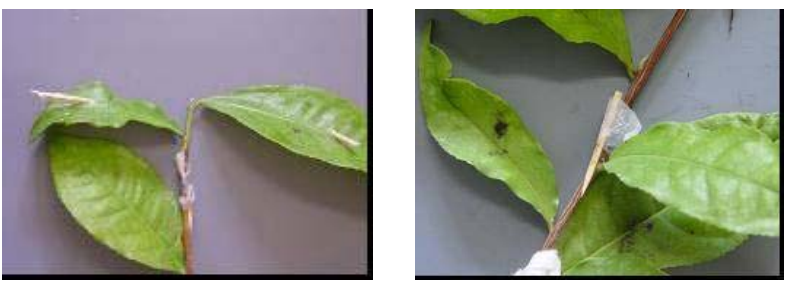

D
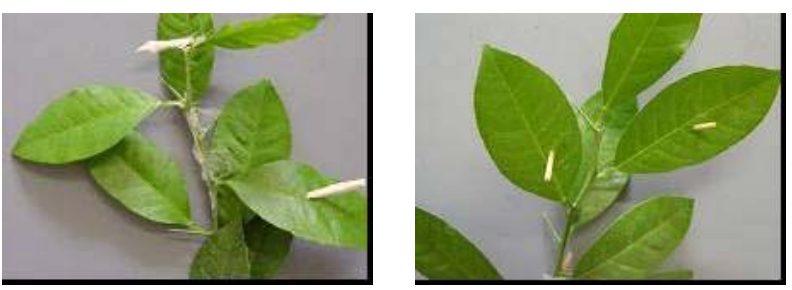

Figura 3. Colonização de ramos destacados de plantas de caqui (A), café (B), chá (C) e citros (D) por Ceratobasidium spp. grupo Diospyrus sob condições de estufa incubadora biológica, sete dias após a inoculação. Ilha Solteira, SP. As testemunhas (não inoculadas de cada uma das espécies testadas são apresentadas à direita. 
sacos plásticos envolvendo os ramos inoculados. Isso, embora facilitasse a manutenção da umidade necessária para colonização dos tecidos pelo fungo, exigiu que a avaliação fosse efetuada aos sete dias após a inoculação. Caso os plásticos fossem mantidos por tempo superior, aumentaria a incidência de amarelecimento e conseqüentemente a queda foliar, inviabilizando a avaliação.

Também não foi possível oferecer às plantas o microclima favorável necessário através do adensamento de plantas. Isto em função do próprio delineamento experimental onde, para se evitar contaminação cruzada por isolados do patógeno, foi mantido espaço entre plantas inoculadas com diferentes grupos de isolados e as não inoculadas. Dessa forma, associados aos demais fatores listados acima, o tempo entre a inoculação e a avaliação foi insuficiente para que a doença pudesse ser expressa em sua magnitude. Acredita-se que o período necessário estaria em torno de 20 dias.

Acredita-se, também, que a seleção dos ramos a serem utilizados para verificar a reação das plantas ao patógeno apresentou papel importante no que diz respeito à severidade da doença e ao aparecimento dos sintomas. A idade fisiológica do material inoculado afetou o desenvolvimento de sintomas mais severos da doença (como por exemplo, a queima de folhas). Tecidos jovens e tenros facilitariam a infecção por parte do fungo e conseqüentemente, o desenvolvimento dos sintomas. Nos testes para se avaliar a patogenicidade cruzada, os ramos das plantas hospedeiras não eram suficientemente jovens e uniformes, implicando como um dos fatores preponderantes para o não desenvolvimento dos sintomas mais severos da doença.

Ao contrário do teste de patogenicidade cruzada, para o teste da reação de cultivares de caqui foi possível a seleção de brotações jovens uniformes para todas as cultivares testadas. Isto facilitou o desenvolvimento de sintomas mais severos da doença devido à idade fisiológica adequada do material inoculado. Utilizou-se ramos mais jovens, com tecido mais tenro, propiciando a infecção por parte do fungo e, conseqüentemente, o aparecimento de sintomas mais severos da doença.

Não foi verificada diferença significativa entre as cultivares de caquizeiro quanto à severidade da doença, não sendo possível identificar fontes de resistência à doença (Tabela 2).

Em estudos futuros, para se inferir se a especialização à hospedeiros é a causa principal para a divergência genética observada entre o grupo Diospyrus e o grupo Camellia de

Tabela 2. Comportamento de oito cultivares de caqui ao fungo do mal-dofio (Ceratobasidium spp. grupo Diospyrus), sob condições de incubação em estufa biológica a $25^{\circ} \mathrm{C}$, sete dias após a inoculação, utilizando-se ramos destacados das plantas oriundas da FEP - UNESP - Campus de Ilha Solteira.

\begin{tabular}{cllc}
\hline Cultivares & \multicolumn{2}{c}{ Mediana } & $\begin{array}{c}\text { Semi-amplitude } \\
\text { interquartíca }\end{array}$ \\
\hline Pomelo & $7,0^{1}$ & $\mathrm{~A}^{2}$ & $\pm 7,0$ \\
Taubaté & 6,0 & $\mathrm{~A}$ & $\pm 5,0$ \\
Rama forte & 4,0 & $\mathrm{~A}$ & $\pm 5,5$ \\
Rubi & 4,0 & $\mathrm{~A}$ & $\pm 3,5$ \\
Fuyu & 5,0 & $\mathrm{~A}$ & $\pm 4,5$ \\
Giro & 7,0 & $\mathrm{~A}$ & $\pm 6,0$ \\
Giombo & 7,0 & $\mathrm{~A}$ & $\pm 6,0$ \\
Fuyhana & 4,0 & $\mathrm{~A}$ & $\pm 4,5$ \\
\hline
\end{tabular}

${ }^{1}$ Média de dez repetições, referentes a dois experimentos analisados conjuntamente;

${ }^{2}$ Medianas seguidas de mesma letra não diferem entre si segundo análise não-paramétrica e teste de múltiplas comparações de Dunn ao nível de 5\% de probabilidade
Ceratobasidium spp., é necessário amostrar populações do fungo oriundas de hospedeiros distintos porém em regiões próximas geograficamente (denominadas de populações simpátricas). Em adição, testes de patogenicidade cruzada com múltiplos isolados do patógeno, geneticamente distintos, são necessários para se detectar variações entre isolados e confirmar a existência e a magnitude da especialização.

\section{AGRADECIMENTOS}

Ao Prof. Dr. Edson L. Furtado por suas sugestões criticas à dissertação de Mestrado da primeira autora; ao Eng. Agr. Mauro Sakai, da APTA Pólo Regional Vale do Ribeira, por nos disponibilizar as plantas de chá e por sua colaboração na amostragem de plantas infectadas pelo fungo, na Fazenda Tea Hills, em Pariquera-açu; ao Prof. Nilton Luiz de Souza (in memoriam), pela colaboração na amostragem do fungo no Vale do Ribeira; à Fundação de Âmparo a Pesquisa do Estado de São Paulo (FAPESP) pela concessão do auxilio financeiro para o desenvolvimento deste estudo (Processo 04/19800); à CAPES, pela concessão de bolsa de estudos à primeira autora durante seu programa de Mestrado em Agronomia pela UNESP Campus de Ilha Solteira; e ao ETH Zurich por financiar parcialmente esta pesquisa (Processo TH16/06-1), viabilizando o seqüenciamento de DNA da região ITS-rDNA para identificação e caracterização filogenética de isolados do patógeno.

\section{REFERÊNCIAS BIBLIOGRÁFICAS}

1. Azevedo, L. A. S. Manual de quantificação de doenças de plantas. São Paulo: Novartis Biociências - Setor Agro, 1998. p. 9-114.

2. Basseto M.A.; Valério Filho W. V.; Costa Souza E.; Ceresini P. C. O papel de Rhizoctonia spp. binucleadas na indução de resistência a mela da soja. Acta Scientiarum Agronomy, Maringá, v. 30, p. 183-189, 2008.

3. Ceresini P. C.; Souza N. L. Associação de Rhizoctonia spp. binucleadas e de $R$. solani Kuhn GA 4 HGI e GA 2-2 III B ao feijoeiro (Phaseolus vulgaris L.) no estado de São Paulo. Summa Phytopathologica, Jaboticabal, v. 23, p.14-23, 1997.

4. Crop Protection Compendium. Corticium koleroga (Cooke) Höhnel. Walingford: CABI. Disponível em: <http:// w w w . c a b i c o m p e n d i u m.o r g / c p c / datasheet.asp?CCODE=CORTKO\&COUNTRY>. Acesso em 25. nov. 2003.

5. Calvacante, M. J. B.; Sales, F. Ocorrência da queima-do-fio (Pellicularia koleroga) em cafezais em Rio Branco. Boletim Técnico Embrapa-Acre, Rio Branco, n.135, p.1-2, 2001.

6. Ceresini, P. C.; Costa Souza, E.; Zala, M.; Furtado, E. L.; Souza, N. L. Divergent populations of the white-thread blight basidiomycete fungal pathogen from persimmon and tea crops in the Brazilian Atlantic Forest agroecosystem share the same mtDNA haplotypes. In: International Rhizoctonia Symposium, 2008, Berlin. Abstr. 4th International Rhizoctonia Symposium. Berlin: Humboldt Universitaet, 2008. p. 48.

7. Fawcett, G. L. Pellicularia koleroga on coffe in Puerto Rico. Journal of Agricultural Research, Lahore. v.2, p.231-233, 1914.

8. Furtado, E. L. Doenças do chá. In: Kimati, H.; Amorim, L.; Bergamin Filho, A.; Camargo, L. E. A.; Rezende, J. A. M. (Ed.) Manual de Fitopatologia, 3.ed. São Paulo: Agronômica Ceres, 1997. v. 2, p.257-260.

9. Gasparotto. L.; Silva, S. E. L. New hosts of Pellicularia koleroga in the State of Amazonas, Brazil. Fitopatologia Brasileira, Brasília, v.24, n.3, p.469, 1999.

10. Kimati, H.; Amorim, L.; Bergamin Filho, A.; Camargo, L. E. A.; Rezende, J. A. M. (Ed.) Manual de Fitopatologia, 3.ed. São 
Paulo: Agronômica Ceres, 1997. v.2, p.257-260.

11. Lourd, M.; Alves, B. L. M. Lista de hospedeiro e etiologia da queima-do-fio das plantas frutíferas na região Amazônica. Fitopatologia Brasileira, Brasília, v.12, p.88-89,1987.

12. Pereira, R. de C. A.; Ledo, F. J. da S.; Bergo, C. L., Siviero, A. Evaluation of arabica and robusta coffee genotypes in western Amazonia. Acta Amazônica, Manaus, v. 30, n.4, p.535-541, 2000.

13. Pereira, R. A.; Takada, H. M.; Ribeiro, I. J. A.; Bueno, S. C. S.; Yanagisawa, S. S.; Freire, I. L. C.; Santos, M. C., Timóteo, W. S. Registro da queima dos fios (Ceratobasidium spp.) em caqui (Diospyros kaki). Fitopatologia Brasileira, Brasília, v.28, Supl., p.90, 2003.

14. Pocinho, M.; Figueiredo, J. P. Estatística e Bioestatística. 2008. Disponível em: <http://biocistron.blogspot.com/search/label/
Bioestat\%C3\%ADstica>. Acesso em 23. out. 2008.

15. Roberts, P. Ceratobasidium noxium (Donk). In: RhizoctoniaForming Fungi. Index Fungorum. Richmond, p.48, 1999.

16. Rosseti, V.; Alves, M. L. B.; Clement, C. Ocorrência de Pellicularia koleroga em pomares cítricos na Amazonas. Fitopatologia Brasileira, Brasília, v.7, p.526, 1982.

17. Siviero, A.; Furtado, E. L.; Boava, L. P.; Barbasso, D. V.; Machado, M. A. Avaliação de métodos de inoculação de Phytophthora parasitica em plântulas e plantas jovens de citros. Fitopatologia Brasileira, Brasília, v.27, n. 6, 2002.

18. Sneh, B.; Jabaji-Hare, S.; Neate, S.; Dijst, G. Rhizoctonia species: taxonomy, molecular biology, ecology, pathology and disease control. Kluwer Academic, Dordrecht. 1996.578p. 